\title{
EXPERIMENTAL INVESTIGATION OF HEAT TRANSFER BETWEEN HOT AIR NOZZLE FLOW AND CYLINDER
}

\author{
Radek ZAHRADNÍK, Jan BOHÁČEK, Petr KOTRBÁČEK•
}

\begin{abstract}
A variety of experimental measurements were performed to clarify the influence of air pressure and distance from a nozzle outlet on the heat transfer intensity between a cylinder's surface and the hot air flowing around the cylinder, which is placed in a rectangular air channel. The surface temperatures of five different surface pointsand air temperatures are recorded during each experiment. The heat transfer coefficient is calculated from the following recorded parameters: air temperature, calculated surface temperature, and heat flux. The surface temperature and the heat flux are obtained from finite element analyses using ANSYS. The boundary conditions for these analyses are taken from the temperature history records. Three different values of air pressures and distances are tested. The distribution of the heat transfer coefficient around the cylindrical surface is determined for these testing conditions. Results are presented in the form of graphs.
\end{abstract}

\section{INTRODUCTION}

The goal of this paper is to present the results from a large set of temperature measurements on a cylinder roll which is heated by hot air in a rectangular air channel. The hot air flows s flowing from outlet nozzles at the bottom of the channel. The measurements were performed to clarify the influence of air pressureand distance from the bottom of the air channel on the heat transfer coefficient (hereinafter referred to asHTC) between the cylinder's surface and the hot air flowing around the cylinder.In addition, the influence of space between the wall of the air channel and the cylinder's surface is observed.

The HTC between the blowing air and the cylinder cannot be measured directly. A knowledge of all the parameters: heat flux, temperature of the cylinder and blowing air is needed for its determination. The temperatures are measured by thermocouples and recorded by a data logger. The heat flux is computed via ANSYS and FEA.

\section{Measurements}

Two different cylinder-air channel geometrical configurations were usedThe first geometrical configuration wasset with an insert which was placed inthe air channel to make the channel narrower. The second configuration was without the insert.The insertreduces the space between the wall of the air channel and the cylinder.

\footnotetext{
•Ing. Radek Zahradník, Ing. Jan Boháček, Ing. Petr Kotrbáček, Ph.D.; Heat Transfer and Fluid Flow Laboratory, Faculty of Mechanical Engineering, Brno University of Technology, Technicka 2896/2; 616 69, Brno; CZ; email: zahradnik@lptap.fme.vutbr.cz, kotrbacek@fme.vutbr.cz;
}

This is an Open Access article distributed under the terms of the Creative Commons Attribution License 2.0, which permits unrestricted use, distribution, and reproduction in any medium, provided the original work is properly cited. 
The cylinder is about 0,3 meters long. The outlet nozzles are installed into the rectangular air channel in a periodical distance of 0,03 meters at the bottom. The sketch of the configuration is shown in Fig. 1. Each nozzle has the same inlet velocity and air pressure during the experiment. Due to this configuration, a unique temperature distribution is only in the area between $0 \mathrm{~mm}$ to $15 \mathrm{~mm}$ at Z-coordinate from the outlet nozzle.

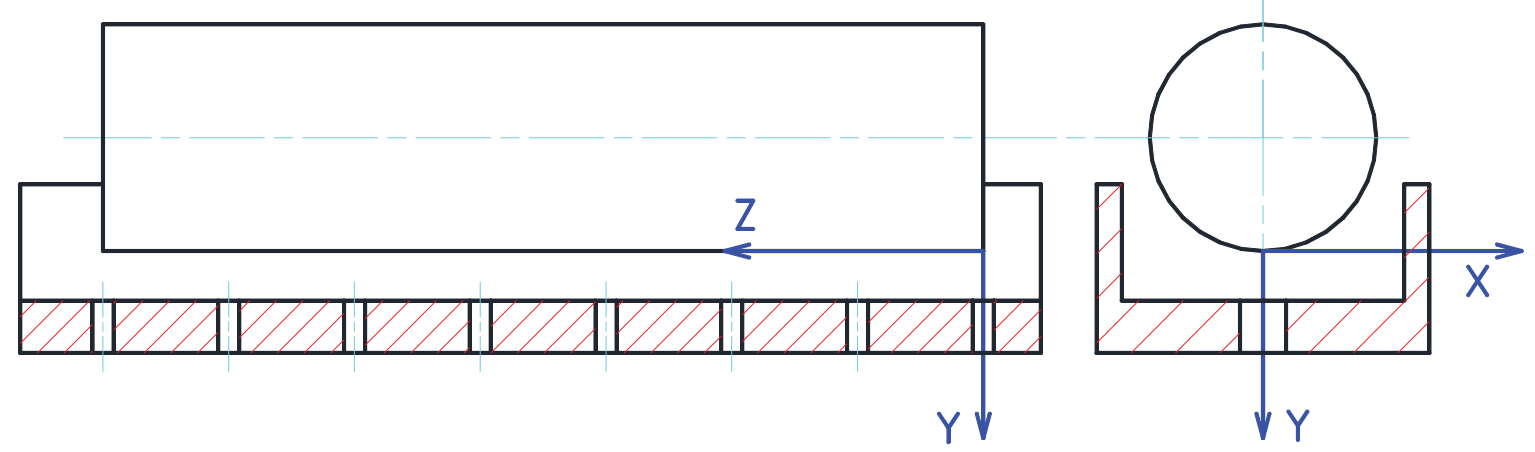

Figure 1: Sketch of axis system used to address results.

The temperatures were recorded for each geometrical configuration in three different places (hereinafter referred to as measurement planes) on the cylinder surface. These measurement planes have different Z-coordinates $(0 / 7,5 / 15 \mathrm{~mm})$. Tests were performedusing three different air pressures $(600 / 350 / 100 \mathrm{~Pa})$ and with three different distances between the cylinder and the bottom of the air channel (14/8/2 mm). This quantity is measured in Y-coordinate (Figure 1 ). The air pressure is measured inside a feeding ducting.
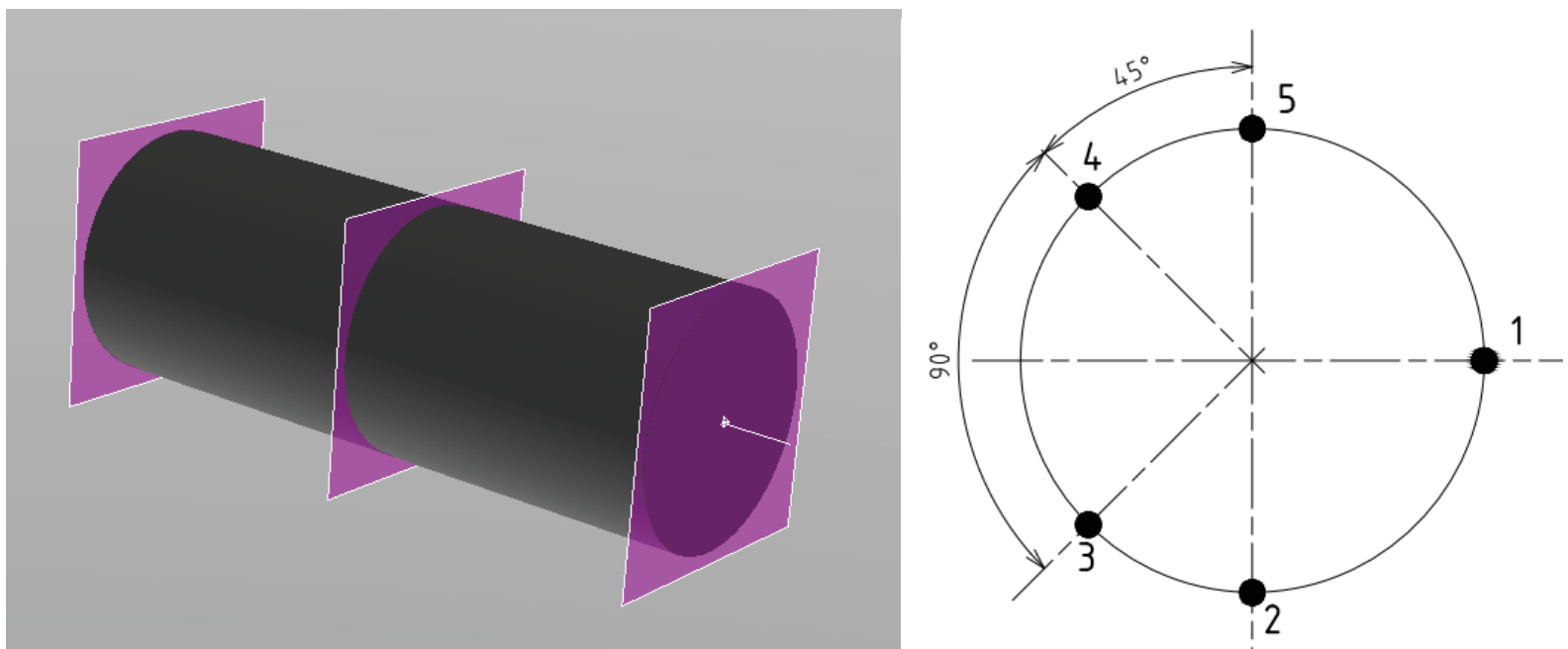

Figure 2: Illustrations of measurement planes where the surface temperatures were recorded (on the left side) and position of thermocouples (on the right side).

\section{Results}

The results are presented in radial charts. The presented results are only from one measurement plane with Z-coordinate $0 \mathrm{~mm}$.Thecharts representthe measurements performed in the same axial distance from the bottom of the air channel.Each chart has 3 curves of HTC distribution around the cylinder's surface. These curves represent 3 
different distances of the cylinder from the outlet nozzle. The blue circle in the middle of each chart represents the cylinder itself. The charts have two axes. The radial axis represents a value of HTC. The peripheral axis (refer to as $\varphi$ ) represents the angular coordinate. The outlet nozzle is placed at $\varphi=180^{\circ}$. Both configurations, with and without the insert, are presented side by side (with/without enclosureon the right/left side) for an easy comparison. The width of air channel is $24 / 36 \mathrm{~mm}$ with/without the insert.The diameter of cylinder is $18 \mathrm{~mm}$.

The temperature records are processed by MATLAB to obtain the envelope boundary condition for transient FEA in ANSYS. A cubic spline interpolation is used to create the discrete temperature field for the whole cylinder surface. This field has 180 values along the radial edge of the cylinder ( 1 value per 1 angular degree). The five values are obtained from measurement, the other valuesare obtained by approximation in MATLAB. In the $Z$-coordinate, the field has 30 values ( 1 value per $1 \mathrm{~mm}$ of length of cylinder). The three of them are measured; the other values are obtained by approximation in MATLAB. The process of obtaining the results from the measurements is fully described in the author's previous work [1].

\section{MEASUREMENT PLANE Z = 0 MM}

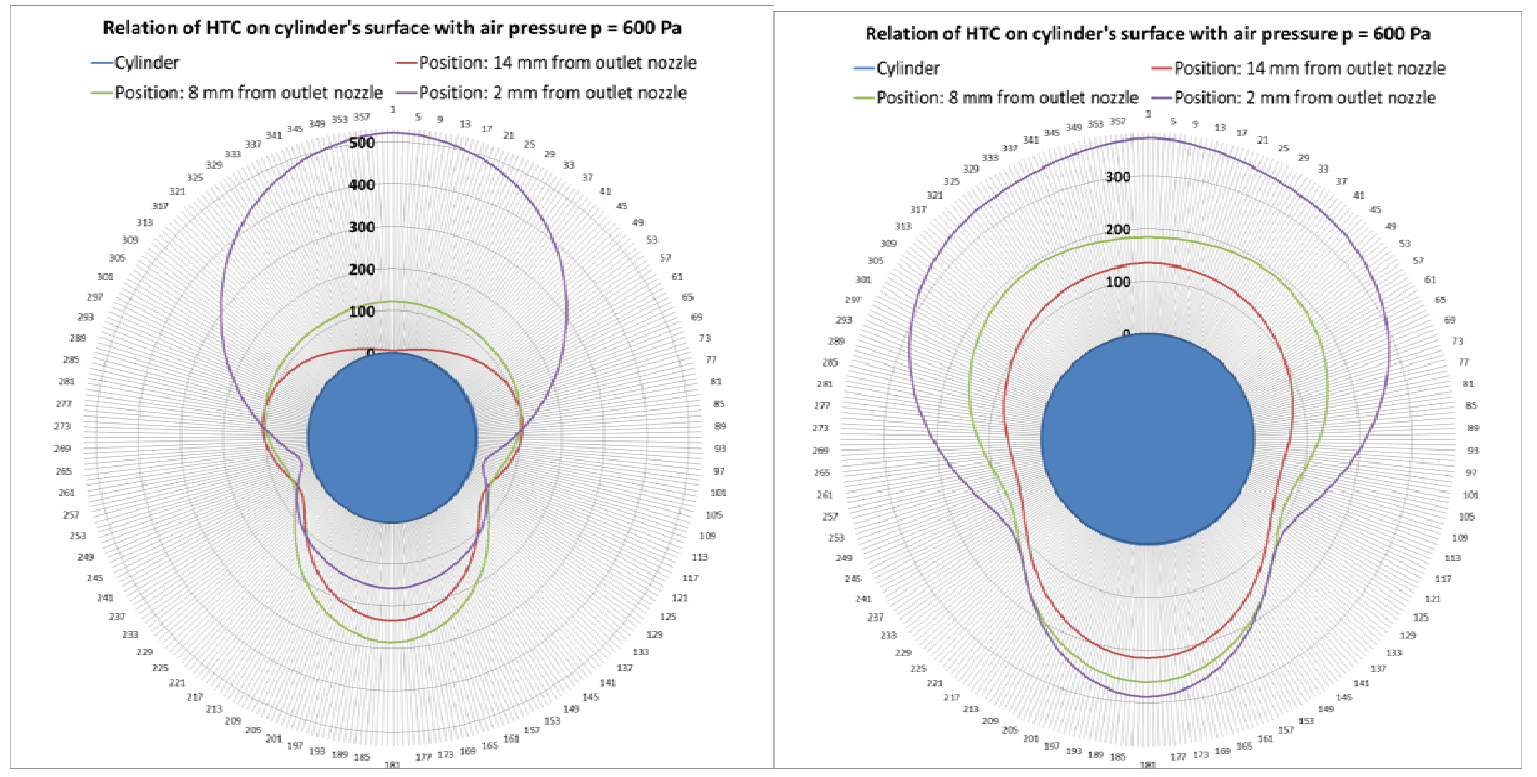

Figure 3, 4: Charts of HTC distribution along cylinder surface for air pressure p $=600 \mathrm{~Pa}$. The radial axis represents a value of HTC. The peripheral axis (refer to as $\varphi$ ) represents angular coordinate. 


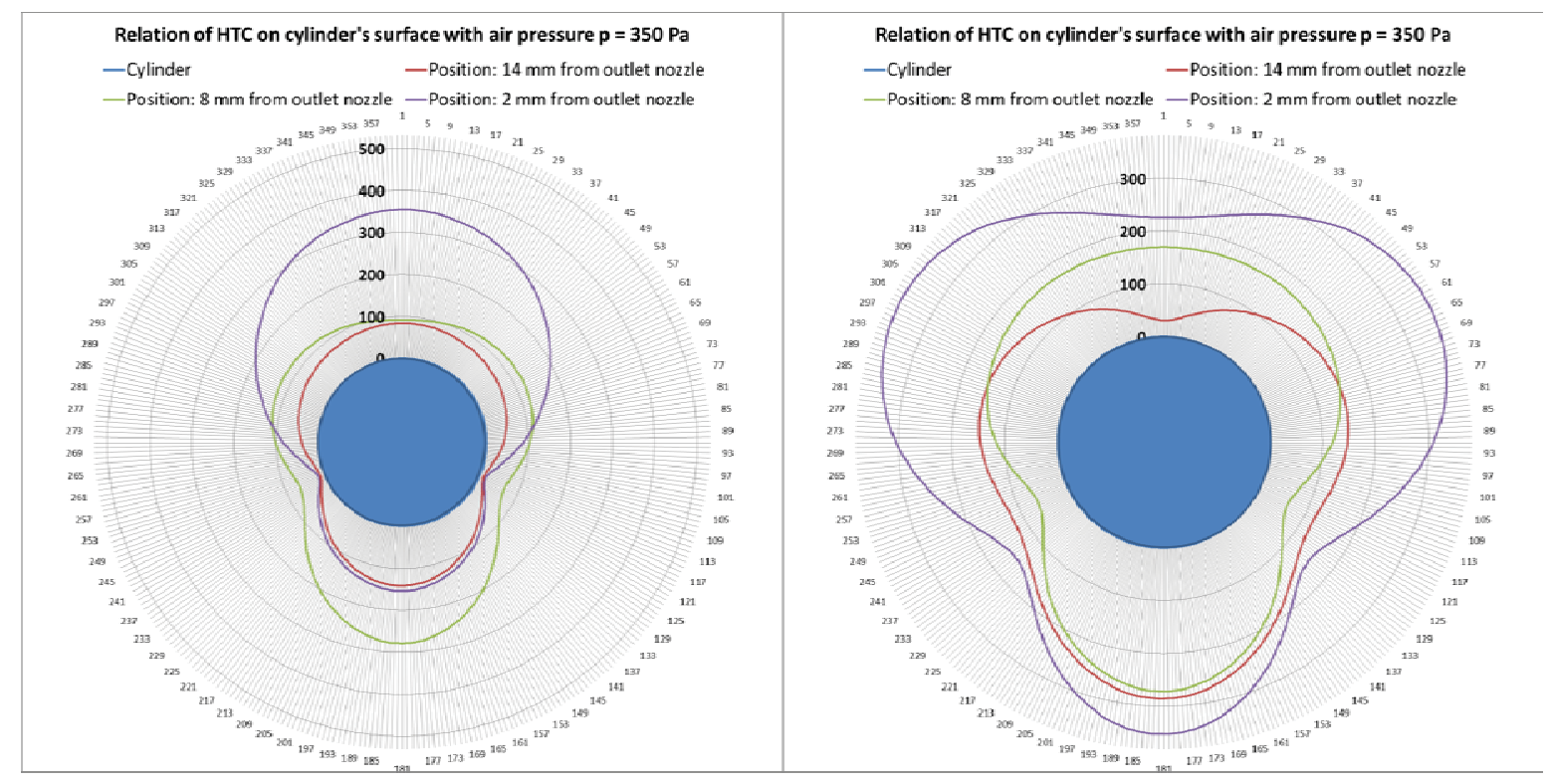

Figure 5, 6: Charts of HTC distributionalong cylinder surface for air pressure $p=$ $350 \mathrm{~Pa}$.The radial axis represents a value of HTC. The peripheral axis (refer to as $\varphi$ ) represents angular coordinate.

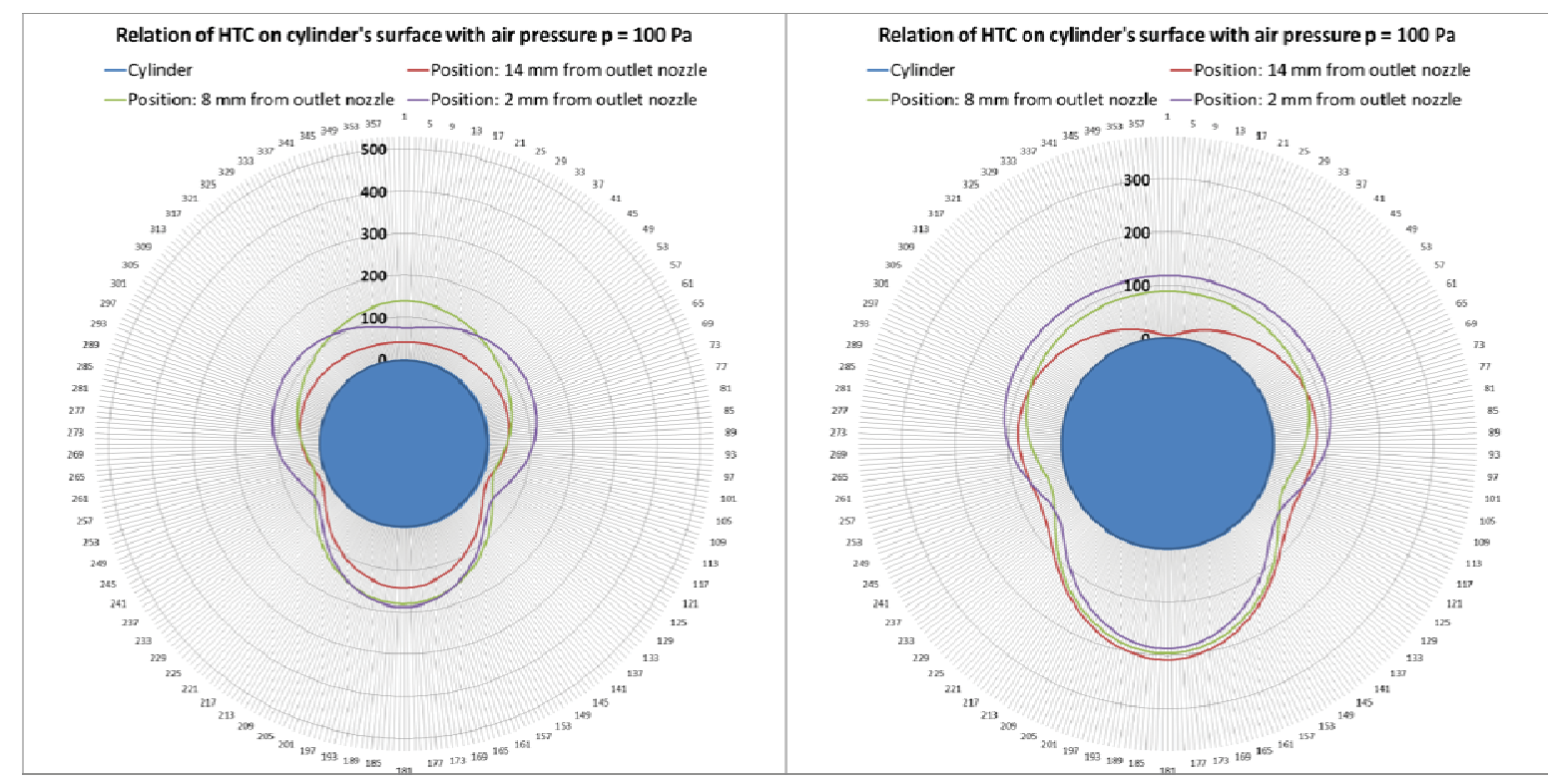

Figure 7, 8: Charts of HTC distributionalong cylinder surface for air pressure $p=$ $100 \mathrm{~Pa}$. The radial axis represents a value of HTC. The peripheral axis (refer to as $\Phi)$ represents angular coordinate. 


\section{Conclusion}

A decrease of HTC to almost zero can be observed on almost each chart. The decrease is located mostly near $\varphi=130^{\circ} / 230^{\circ} \pm 15^{\circ}$. This is most likely because of a disruption of air flow.

The geometrical configuration without the insert shows higher values of HTC in most cases as we can see in Figures 4 and 6. The higher values of HTC aremost likely because of a slower cross flow around the cylinder.

The unambiguous correlation between the distance of the cylinder and the bottom of the air channel can be seen with configuration without insert. Figures 4 and 6 show that the HTC values are distributed according to their $\mathrm{Y}$-coordinate value and air pressure $600 / 350 \mathrm{~Pa}$. Figure 8 shows that the HTC values are almost identical in the experiment with air pressure $100 \mathrm{~Pa}$.

The geometrical configuration with insert does not directly correlate between HTC values and distance in Y-coordinate. Figures 3 and 5 show that the distance $8 \mathrm{~mm}$ between the cylinder and bottom of the air channel produces the highest value at the bottom of the cylinder. A wake created during the test with the distance $2 \mathrm{~mm}$ between the cylinder and bottom of the air channel shows the highest value at the top of cylinder (figure 3,5 ).

\section{ACKNOWLEDGMENTS}

The paper presented has been supported by the internal grant of the Brno University of Technology focused on specific research and development No. FSI-S-11-20 - Heat Transfer Intensification.

\section{REFERENCES}

[1] Zahradník R., Kvapil J.: Algorithm for Calculation of heat transfer coefficient of cylindrical bar blown by hot air, Svratka, Engineering Mechanics, 2011, 675-678

[2] Incropera F. P., DeWitt D. P.: Fundamentals of Heat and Mass Transfer, 5th Edition, USA, Wiley, 2001

[3] BASKIYAR, R. Finite element method simulation of the cooling of hot-rolled steel rods. Heat Transfer Engineering, Dec 2004, vol. 25, no. 8, p. 94-98.

[4] HUANG, S.H., KIM, J.Y. AND CHUN, C.H. Numerical simulations of turbulent mist flow and conjugate heat transfer in a cooling device of moving hot steel rod. edited by F. ZHUANG AND J.C. LI. Edtion ed., 2004. 555-559 p. ISBN 7-30208817-9.

[5] KARAYIANNIS, T.G., SHIFERAW, D., KENNING, D.B.R. AND WADEKAR, V.V. Flow Patterns and Heat Transfer for Flow Boiling in Small to Micro Diameter Tubes. Heat Transfer Engineering, 2010, vol. 31, no. 4, p. 257-275.

[6] SANCHEZSARMIENTO, G., MUES, E. AND BUNTE, C. Application of computer models to the determination of heat transfer coefficients of UCON $(R)$ quenchant solutions in heat treating operations. edited by G.E. TOTTEN, M.A.H. HOWES, S. SJOSTROM AND K. FUNATANI. Edtion ed., 1996. 275-281 p. ISBN 0-87170-5842.

[7] SANKAR, I.B., RAO, K.M. AND KRISHNA, A.G. Prediction of heat transfer coefficient of steel bars subjected to Tempcore process using nonlinear 
modeling. International Journal of Advanced Manufacturing Technology, Apr 2010, vol. 47, no. 9-12, p. 1159-1166.

[8] SHA, X.C., LI, D.Z., LAN, Y.J., ZHANG, X.G. AND LI, Y.Y. Modelling the temperature distribution along the length of strip during hot rolling process. Steel Research International, May 2004, vol. 75, no. 5, p. 330-338.

[9] VISSER, J.A. AND MATHEWS, E.H. NUMERICAL MODELING OF THE HEATTRANSFER IN AND AROUND A STEEL BAR DURING HOT-ROLLING. Communications in Applied Numerical Methods, Sep-Oct 1988, vol. 4, no. 5, p. 657-664. 